\title{
EDUCAÇÃO A DISTÂNCIA E ENSINO REMOTO: DISTINÇÕES NECESSÁRIAS
}

\author{
DISTANCE EDUCATION AND REMOTE EDUCATION: \\ NECESSARY DISTINCTIONS
}

\author{
Eder Alonso Castro ${ }^{1}$ \\ Eliziane Rodrigues de Queiroz ${ }^{2}$
}

\begin{abstract}
Resumo: 0 presente estudo se define por uma pesquisa qualitativa que visa conceituar a educação a distância- EAD em suas diferentes manifestações, assim como a utilização de atividades remotas no intuito de substituir aulas presenciais em virtude da epidemia do COVID - 19. Partiu-se da preocupação do uso incorreto da sigla EAD para designar qualquer atividade educacional a ser executada neste momento de isolamento social. A preocupação dos autores foi a de ouvir estudantes e docentes que estejam passando pela experiência das atividades não presenciais e perceber seus sentimentos e dificuldades neste momento singular que estamos vivendo. Nesse sentido, elaboramos questionários que foram respondidos por estudantes e docentes e analisamos suas respostas como forma de resultado de nossa pesquisa. Dos dados mais curiosos da pesquisa vale citar as dificuldades de ambientação com a tecnologia, assim como as complicadas condições de organização de espaço e tempo para executar as atividades em ambiente domiciliar. Tais dificuldades foram relatadas tanto por estudantes quanto pelos docentes. Outro fato importante está na falta de planejamento e capacitação docente apropriada para execução de atividades não presenciais.
\end{abstract}

Palavras-chave: Educação a Distância, Educação em Tempos de Pandemia, Mediação Pedagógica.

Abstract: The present study is defined by a qualitative research that aims to conceptualize distance education - EAD in its different manifestations, as well as the use of remote activities in order to replace face-to-face classes due to the COVID epidemic 19. It was based on the concern the incorrect use of the acronym EAD to designate any educational activity to be carried out at this time of social isolation. The authors' concern was to listen to students and teachers who are going through the experience of non-faceto-face activities and to understand their feelings and difficulties in this unique moment that we are living. In this sense, we developed questionnaires that were answered by students and teachers and analyzed their responses as a result of our research. From the most curious data of the research, it is worth mentioning the difficulties of setting up with technology, as well as the complicated conditions of organizing space and time to perform activities in the home environment. Such difficulties were reported by both students and teachers. Another important fact is the lack of planning and appropriate teacher training toperform non-classroomactivities.

Keywords: Distance Education, Education in Times of Pandemic, Pedagogical Mediation.

\footnotetext{
1 Graduação em Pedagogia, Filosofia e Artes, Mestrado e Doutorado em Educação. Professor da área de educação do Instituto Federal de Brasília- IFB, Campus Gama. Orcid: https://orcid.org/0000-0001-5618-111X

2 Graduada em Pedagogia, mestre em Educação e Pedagoga do Instituto Federal de Ciência e Tecnologia de Brasília IFB, Campus Gama. Orcid: https://orcid.org/0000-0001-5072-2448
} 


\title{
1. Introdução
}

No final do ano de 2019, quando ouvíamos falar de uma doença que assolava a China, nem podíamos imaginar que o mundo todo seria abalado pela COVID-19. Iniciamos 2020 acreditando que não seríamos atingidos por tamanha desgraça. Mas, sorrateiramente o vírus foi se espalhando pelo mundo e hoje nos encontramos em uma situação inimaginável há tempos atrás.

De repente a pandemia. 0 mundo todo assustado e buscando soluções para amenizar a crise em todos os setores da sociedade. A saúde, a economia, a educação, as relações sociais, enfim, a humanidade como um todo, passou a viver com incertezas e medos até então não considerados.

Conforme Sousa Santos (2020) a crise social não começou com a pandemia da COVID-19, mas está instaurada desde a década de 1980, quando o neoliberalismo vem se impondo como nova versão do capitalismo e, a partir de então, vivemos uma crise financeira permanente que é utilizada para justificar os cortes nas políticas sociais (saúde, educação e previdência social).

\begin{abstract}
... Por isso, a pandemia, vem apenas agravar uma situação de crise que a população mundial tem vindo a ser sujeita. Daí a sua específica periculosidade. Em muitos países os serviços públicos de saúde estavam mais bem preparados para enfrentar a pandemia há dez ou vinte anos do que estão hoje. (SOUSA SANTOS. 2020. p. 6)
\end{abstract}

Em virtude dessa situação, a pandemia se torna mais enfática e assustadora revelando as diferenças sociais e tornando públicas as situações de miséria que grande parte da população mundial vive. Tal situação escancarou as diferenças e expôs as fragilidades humanas. Assim, a quarentena não é a mesma para todos, ganha diferentes significados em diferentes contextos com uma diversidade de vivências que não podem ser generalizadas ou universalizadas.

Sendo a escola um local de concentração de muitas pessoas e, ao mesmo tempo, um local de grande circulação, em diferentes lugares do mundo, ela foi um dos primeiros equipamentos sociais que teve suas atividades paralisadas. Inicialmente, acreditava-se que essas paralisações seriam curtas e logo tudo voltaria ao normal. Mas, com o tempo percebeu-se que a volta à normalidade não se daria com tanta rapidez. Ou ainda, que voltar à normalidade não seria mais possível. Diante desta situação de isolamento social como fica a educação escolar?

É difícil falar de educação escolar ontologicamente. Os diferentes níveis e as diferentes realidades fazem com que a educação escolar tenha muitas formas e manifestações. Neste texto vamos focar a educação brasileira em tempos de pandemia, na busca de melhor delimitação discutiremos a educação superior e as diversas saídas encontradas para driblar o isolamento social.

Mesmo focando a educação superior brasileira, estamos nos referindo a diferentes realidades em diversos contextos. Uma das primeiras discrepâncias se

Rev. Nova Paideia -Revista Interdisciplinar em Educação e Pesquisa Brasília/DF, v. 2, n. 3. Núm. Esp.. p. 3 - 17 - ANO 2020 ISSN 2674-5976 
apresenta na diferença entre a educação superior privada e a pública, duas realidades distintas com objetos comuns, mas com meios e fins distintos. Se formos aprofundar a questão ainda dentro das instituições, teremos as diferenças de um tipo de curso para outro. Mas nosso objetivo, neste estudo, é o de identificar como as instituições de ensino superior - IES vêm enfrentando o isolamento social na manutenção das atividades educacionais em tempos de pandemia.

É sabido que muitas universidades, centros universitários e faculdades suspenderam seus calendários acadêmicos e estão com todas as atividades de ensino paralisadas. Em algumas delas as atividades de pesquisa continuam existindo (em andamento) e em outras tanto o ensino, a pesquisa quanto à extensão estão desativadas (suspensas). Estas IES não nos interessam neste estudo. Nosso objeto de análise serão aquelas instituições que buscaram formas de manter suas atividades de ensino por meio de atividades não presenciais.

Na mídia, muitas vezes, ouvimos que as atividades não presenciais, ofertadas pelas IES durante o tempo de isolamento social, são atividades de ensino a distância - EAD. Esse fato pode causar sérios prejuízos à compreensão do significado dessa modalidade educacional e da sua importância para a educação brasileira. A esse respeito, cabe ressaltar a conceituação atribuída ao termo "atividades não presenciais", no Parecer CNE no 5/2020, referindo-se a elas como "aquelas a serem realizadas pela instituição de ensino com os estudantes quando não for possível a presença física destes no ambiente escolar" (BRASIL, 2020). A Comissão apresenta as atividades não presenciais apenas como uma alternativa pedagógica para evitar retrocessos no processo de aprendizagem dos estudantes e a perda dos vínculos com a escola que podem convergir como fatores de evasão e abandono.

Portanto, neste texto, buscaremos esclarecer que tais atividades não podem ser generalizadas como educação ou ensino a distância pela complexidade que esta modalidade requer em sua implementação e, por isso, não pode ser de entrega rápida ou "delivery" como tem sido as atividades remotas oferecidas pela maioria das instituições.

Buscaremos, também, analisar as impressões de professores e estudantes, que estão passando pela experiência de elaborar e de realizar tais atividades. Nesta análise discutiremos os formatos de atividades remotas e a importância do uso das tecnologias como ferramentas educacionais. Discutiremos, também, o papel do professor nesta modalidade educacional e a necessidade de uma qualificação específica para o exercício de funções específicas de mediação pedagógica.

Durante muito tempo a educação escolar resistiu às mudanças econômicas, sociais, comportamentais e quebras de paradigmas. 0 ciclo evolutivo da humanidade foi marcado por um conjunto de mudanças, que alteraram o eixo econômico-político-social, mas a escola manteve seu modelo de ensino muito próximo daquilo que era na idade média e no início da modernidade. Talvez este momento de Pandemia, seja capaz de demonstrar que é possível fazer uma educação escolar mais próxima da realidade dos estudantes da geração " $Y$ " e "Z".

Rev. Nova Paideia -Revista Interdisciplinar em Educação e Pesquisa Brasília/DF, v. 2, n. 3. Núm. Esp.. p. 3 - 17 - ANO 2020 ISSN 2674-5976 
Entendemos que este momento de crise humanitária seja um momento privilegiado para que educação escolar possa dar o salto necessário para alcançar a sociedade 4.0 .

\section{Resgatando o conceito de Educação a Distância}

Embora oficialmente instituída como uma modalidade educacional há pouco mais de duas décadas, a EaD não é uma prática pedagógica recente no Brasil. Sua trajetória histórica tem origem por volta de 1900 quando se tem notícia da ousada publicação particular de uma professora divulgando, em um jornal de grande circulação no Rio de Janeiro, sobre a oferta de curso profissionalizante em Datilografia, por correspondência, (Alves, 2011). Desde então, a EaD vem crescendo e se desenvolvendo como uma modalidade de ensino possível de ser realizada nos diferentes níveis e categorias da educação, apoiada em diferentes recursos tecnológicos que vêm evoluindo ao longo da história, tais como a imprensa, o rádio, a telefonia, a televisão, o computador e o smartphone.

Quanto aos aspectos regulamentares, a EaD somente é legalmente reconhecida como modalidade educacional a partir da Lei de Diretrizes e Bases da Educação Nacional (LDB), Lei 9.394, de 20 de dezembro de 1996. Na perspectiva de uma modalidade educacional, podemos afirmar que a EaD apresenta um modo diferenciado de fazer a prática educativa, o que inclui o uso diferenciado de metodologias, recursos tecnológicos, políticas de acesso, e regramentos legais instituídos em âmbitos nacional e institucional.

Ao analisarmos a modalidade do ponto de vista científico, muitos estudiosos apresentam um conceito da EaD tomando como ponto de partida o critério de distanciamento físico entre os participantes, enfatizando as relações de tempo e espaço entre os atores do processo ensino-aprendizagem. Na concepção de Beloni (2015), esse parâmetro busca uma conceituação da EaD a partir do que ela não é, ou seja, uma modalidade presencial. Essa perspectiva de conceituar a EaD a partir da comparação com a educação presencial talvez faça com que muitos cometam o equívoco de julgar uma modalidade melhor ou pior que outra.

Do ponto de vista normativo, o conceito de EaD vem sofrendo modificações que revelam o grau de amadurecimento com relação à concepção da modalidade como uma proposta educacional que possui especificidades que requerem qualificação profissional e investimentos governamentais. 0 foco da análise no presente artigo, no que se refere ao resgate do conceito de EaD no Brasil, se atém ao que prevê o Decreto 9.057/2017, que vigora como o conceito legalmente instituído:

Art. 1o - Para fins deste Decreto, considera-se educação a distância a modalidade educacional na qual a mediação didático-pedagógica nos processos de ensino e aprendizagem ocorra com a utilização de meios e tecnologias de informação e comunicação, com pessoal qualificado, com políticas de acesso, com acompanhamento e avaliação compatíveis, entre outros, e desenvolva atividades 
educativas por estudantes e profissionais da educação que estejam em lugares e tempos diversos". (Brasil, 2017)

A priori, tomemos como ponto de análise a caracterização da EaD como "modalidade educacional na qual a mediação didático-pedagógica nos processos de ensino e aprendizagem ocorra com a utilização de meios e tecnologias de informação e de comunicação". Ao refletirem sobre a concepção de mediação pedagógica, Perez e Castilho (1999) afirmam que

\begin{abstract}
A mediação pedagógica busca abrir um caminho a novas relações do estudante: com os materiais, com o próprio contexto, com outros textos, com seus companheiros de aprendizagem, incluído o professor, consigo mesmo e com seu futuro. (PEREZ e CASTILHO, 1999, p. 10)
\end{abstract}

Entendemos, portanto, que a mediação pedagógica se estabelece como uma rede que cria conexões entre os diversos elementos que compõem a prática educativa, desde os materiais didáticos até os companheiros de partilha de experiências de aprendizagem, tendo como foco o estudante. Essa mediação pedagógica no contexto da EaD deve necessariamente apoiar-se em recursos tecnológicos de informação e de comunicação que se apresentam como meios para que esse processo de mediação pedagógica aconteça.

Masetto (2000) ao propor o uso de novas tecnologias para a mediação pedagógica se refere às "novas tecnologias" como aquelas ditas digitais ou por meio do computador. Para o autor, as técnicas didáticas devem ser integradas aos recursos tecnológicos e sempre com foco no propósito educacional, ou seja, no que se pretende que os alunos aprendam. Nesse sentido, a tecnologia passa a ter um valor relativo que ganha significado à medida que for sendo adequada ao alcance dos objetivos de aprendizagem.

Dessa forma, entendemos que a mediação didático-pedagógica na EaD requer um planejamento de ensino necessariamente apoiado por tecnologias digitais adequadas aos objetivos de aprendizagem onde o processo de construção do conhecimento acontece por meio de conexões estabelecidas entre todos os elementos que compõem o processo ensino-aprendizagem. Esse planejamento, portanto, não se dá de forma pontual, mas deve acontecer em uma perspectiva integral e contínua.

A importância das tecnologias digitais, nesse contexto, nos permite ressignificar o conceito de presencialidade, tanto na perspectiva de temporalidade quanto de espacialidade, no sentido de que ela torna possível que aos partícipes do processo educacional realizem suas atividades de forma síncrona e em um espaço virtual coletivo comum. Por isso, o foco da conceituação deixa de ser a separação física e espacial, podendo essa barreira ser superada, desde que sejam utilizadas estratégias didáticas adequadas e integradas aos recursos tecnológicos. 
Um segundo aspecto do conceito apresentado no Decreto $9057 / 2017$, foco da presente análise, reside da necessidade de "pessoal qualificado". Esse, de fato, é um avanço muito importante no conceito de EaD dentro da concepção normatizadora brasileira com relação aos dois conceitos constantes nos decretos anteriores.

Mill e Silva (2018, p.550), afirmam que "entre as grandes dificuldades das instituições de ensino, no que diz respeito a implantar cursos pela Educação a Distância, está a definição de recursos humanos qualificados para executar um trabalho de qualidade". Tomando como foco a qualificação docente, os autores consideram que a prática da docência na EaD requer maior especialização do professor que geralmente enfrenta vários desafios no início de sua experiência com a modalidade e por isso necessita de uma formação específica.

A qualificação na EaD abrange diferentes áreas, percorrendo pelos conhecimentos relacionados à educação, informática, comunicação, psicologia, gestão, entre outras. Primeiramente, por se tratar de um modo de educação, e é sempre muito importante ressaltar que educação a distância é, antes de tudo, educação, para Mill et al. (2014b, p. 128), "a formação de educadores para a EaD aparece como fator de extrema importância no que tange a qualidade de ensino e, portanto, não deveria ser tomada como idêntica à formação do educador para a educação presencial".

Mill (2012), ao abordar a natureza da atividade docente na EaD introduz o conceito de polidocência que se caracteriza pela natureza coletiva e fragmentada das atividades docentes. A polidocência propõe um modelo de trabalho de equipe multidisciplinar no qual cada integrante desenvolve funções específicas que convergem para um produto final, ou seja, a oferta de um curso ou disciplinas a distância. Dentre esses profissionais elencamos: professor-autor, designer instrucional, tutor, professor-coordenador ou professor-formador, pedagogo, revisor textual, web designer, etc. Nessa perspectiva, a prática da docência é realizada a muitas mãos o que permite uma superação da solidão pedagógica muitas vezes presente na prática docente da educação presencial. No entanto, atentamos para o cuidado de não abordar a polidocência sob a ótica fordista de linha de produção onde a fragmentação impede completamente a interlocução didática da prática formativa. Nesse sentido, entendemos que os fatores institucionais definirão as qualificações e os modelos pedagógicos a ser desenvolvido na EaD.

\section{Metodologia}

O estudo se configura como uma pesquisa de campo descritiva e qualitativa, que visa analisar a utilização de atividades a distância na educação escolar em tempos de pandemia. Inicialmente, caracterizamos o que se entende por atividades não presenciais e por educação a distância, buscando na literatura os conceitos e a legislação que embasam e EAD no Brasil. Na sequência elaboramos dois questionários, um direcionado a estudantes e outro a docentes que estão vivenciando a experiência de atividades remotas durante o período de distanciamento social.

Rev. Nova Paideia -Revista Interdisciplinar em Educação e Pesquisa Brasília/DF, v. 2, n. 3. Núm. Esp.. p. 3 - 17 - ANO 2020 ISSN 2674-5976 
Nosso objeto de estudo em análise é o conceito que se tem popularizado de EAD neste período emergencial da pandemia do COVID - 19 e em que condições tais atividades estão sendo realizadas. A perspectiva de comparação se dará entre as respostas colhidas dos docentes e dos estudantes relacionadas aos fundamentos da EAD.

Os questionários foram realizados na plataforma do "Google Docs" e distribuídos, aleatoriamente, por meio de diversos grupos de redes sociais. Coube a nós realizar o estudo, a análise, o registro e a interpretação dos fatos colhidos por meio das respostas de docentes e estudantes, sem realizar a manipulação ou interferência de tais respostas.

É uma pesquisa de abordagem qualitativa porque estuda os aspectos subjetivos do fenômeno social que é a oferta de atividades escolares na educação superior, de forma remota, em uma situação emergencial como essa que estamos vivendo. Nesse sentido, pode ser identificada como um estudo de caso pelo fato de fazer a análise, de maneira aprofundada, dessa situação específica. Os sujeitos da pesquisa, tanto os docentes quanto os estudantes, não se encontram em uma determinada instituição ou localização, foram contatados por meios digitais em diversos grupos de redes sociais.

\section{Resultados e Discussão}

Os questionários foram disponibilizados aos sujeitos da pesquisa no período de quinze dias, entre os meses de maio e junho do corrente ano, por meio de diversas redes sociais. Obtivemos respostas de 60 (sessenta) docentes e 121 (cento e vinte e um) de estudantes da educação superior que estão vivenciando atividades não presenciais durante o período de isolamento social. Passaremos a analisar as resposta comparativamente entre os dois tipos de respondentes: estudantes e docentes das questões que foram concomitantes aos dois tipos de sujeitos.

A primeira questão era sobre o tipo de instituição a qual estavam vinculados: pública ou privada. Obtivemos como respostas que $66,1 \%$ dos estudantes são de instituições privadas e $33,9 \%$ são de instituições públicas. Em relação aos docentes $66,1 \%$ pertencem às instituições privadas e 33,9\% são de instituições públicas. Identificamos nesses dados uma coerência entre os quantitativos o que nos leva a inferir que a maioria das IES que estão ofertando atividades remotas são instituições privadas.

A segunda questão indagava sobre como a IES define as atividades realizadas durante o período da pandemia. Os estudantes responderam: 50,4\% que a IES denomina as atividades como "Atividades Remotas", para 28,1\% tratam como "EAD" e 18,2 afirmam que são chamadas de "Aulas não presenciais". Para os docentes: 68,3\% denominam de Atividades Remotas", para outros 15\% chamam de "Aulas ou Atividades não Presenciais" e para 10\% nomeiam de "EAD".

Percebe-se aqui uma diferença de compreensão entre as respostas dos estudantes e dos docentes. Enquanto mais de $28 \%$ dos estudantes afirmam que suas IES denominam as atividades como EAD apenas $10 \%$ dos docentes afirmam o mesmo. Talvez a diferença esteja na compreensão da atividade que, como afirma Beloni (2015), 
toda atividade que não é presencial passa a ser caracterizada, erroneamente, como EAD. Talvez, para o docente este conceito de EAD esteja mais claro do que para os estudantes.

A terceira questão indagava se os sujeitos haviam sido consultados, pela instituição, sobre a disponibilidade de acesso aos recursos tecnológicos para realização das atividades. Dos estudantes, 66,9\% afirmaram que não foram consultados e os outros disseram que sim. Quanto aos docentes $88,3 \%$ responderam que não foram consultados e apenas $16,7 \%$ afirmaram que sim. Podemos inferir que a grande maioria dos sujeitos não foi consultada sobre as condições de acesso aos meios tecnológicos e com isso podemos supor que as IES partem do princípio de que todos têm acesso e domínio das tecnologias. Essa suposição pode ser bastante precipitada e conter nela um ranço de exclusão que muitas vezes não é perceptível a olho nu. Outro aspecto que se evidencia nessas respostas é a falta de planejamento para implementação de novas metodologias como afirma Masetto (2000), se as atividades ferramentas educacionais não forem integradas ao propósito educativo dificilmente elas obterão sucesso.

A quarta questão indagava sobre o acesso aos recursos tecnológicos necessários à realização das atividades não presenciais. $79,3 \%$ dos estudantes afirmam ter acesso facilmente a todos os recursos tecnológicos, enquanto que $20,7 \%$ dizem ter acesso à parte dos recursos necessários para realização das atividades. No tocante aos docentes $73,3 \%$ dizem ter acesso facilmente a todos os recursos tecnológicos e outros $25 \%$ afirmaram ter acesso à parte dos recursos necessários para realização das atividades. Desses dados podemos inferir que a maior parte dos sujeitos possui acesso aos meios tecnológicos.

A quinta questão solicitava aos respondentes que avaliassem o grau de dificuldade com relação ao uso dos recursos tecnológicos necessários à realização das atividades não presenciais. Dentre os estudantes detecta-se que $64,4 \%$ não apresentam dificuldades na utilização dos recursos, 23,1\% apresentam dificuldades medianas, enquanto que $12,4 \%$ apresentam algum tipo de dificuldade. Quanto aos docentes $56,6 \%$ não apresentam dificuldades na utilização dos recursos, 31,7\% apresentam dificuldades medianas, enquanto que $11,7 \%$ apresentam algum tipo de dificuldade. Nesta comparação inferimos que possivelmente, a diferença de idade entre estudantes e docentes faz com que os primeiros tenham menos dificuldades na utilização de recursos tecnológicos em virtude de serem nativos das novas TICs.

A sexta questão indagava sobre a quantidade de atividades que estão sendo realizadas comparadas com as aulas presenciais. Para os estudantes, $42,1 \%$ julgam que as atividades estão um pouco acima do normal, outros $26,4 \%$ acreditam que estão na mesma proporção, $19 \%$ acha que está muito acima da quantidade de atividades e 12,4 acredita que está abaixo da quantidade de atividades solicitadas durante o período normal. Para os docentes essas porcentagens variam entre: $31,7 \%$ acreditam que a quantidade de atividades está muito acima das realizadas durante o período normal, $28,3 \%$ julgam que está um pouco acima, $26,7 \%$ acha que está na mesma proporção e $13,3 \%$ percebe que está abaixo da quantidade de atividades realizadas durante o período normal. Neste aspecto podemos identificar que os índices apresentados nas respostas de estudantes e docentes estão aproximados. Mais uma vez recorremos a 
Masetto (2000) que afirma que a falta de planejamento e nesse caso um planejamento docente coletivo poderia dirimir o excesso de atividades que possa ocorrer.

Uma das questões foi aberta e solicitava aos estudantes e docentes que descrevessem os principais desafios e dificuldades que vivenciaram na realização das atividades acadêmicas não presenciais. No intuito de condensar as respostas criamos quatro categorias para classificá-las: Dificuldades tecnológicas, dificuldades de Organização e gestão do tempo, dificuldades ambientais e dificuldades psicológicas.

Nas dificuldades tecnológicas os estudantes apontam o acesso à rede de internet como maior empecilho para acompanhar as atividades remotas, principalmente aquelas que são síncronas. As reclamações giram em torno da baixa qualidade do sinal de internet, assim como, da inconstância na rede. Outra crítica forte está relacionada às plataformas utilizadas por algumas IES que não oferecem recursos necessários para realização de determinadas atividades. Uma queixa recorrente recai sobre a dificuldade de acesso a programas solicitados pelos professores para realizar determinadas tarefas remotas e acesso a bibliotecas, o que impede a realização de alguns estudos. Apresentam dificuldade muito grande em relação a matérias que necessitam de aulas práticas e o fato de não estar tendo esse tipo de aula estar afetando no aprendizado. E por último, a falta de experiência tanto dos docentes como dos estudantes em lidar com as ferramentas tecnológicas, esse fato interfere e atrapalha o processo de ensino e aprendizagem. Também quanto ao acesso à rede online, os docentes corroboram com os estudantes, afirmando que muitos têm dificuldades de conexão de internet. Apresentam que a falta de familiarização dos professores com as ferramentas digitais dificulta na elaboração e disponibilização de materiais didáticos e pelo fato da urgência provocada pela pandemia não houve tempo de ter uma formação adequada, o que revela a falta de capacitação e a inexperiência com a EAD. Outro aspecto que esta situação desvelou é a cultura da educação tradicional e "bancária", como conceitua Paulo Freire, os estudantes não estão acostumados com a autonomia na aprendizagem.

No que tange às dificuldades de organização e gestão do tempo entre os estudantes, a maioria dos respondentes afirma ter dificuldade na organização do tempo para conciliar diversas atividades. Esta dificuldade está associada ao fato de estarem no ambiente doméstico no qual muitos fatores interferem na gestão do tempo. Muitos estudantes são, ou convivem commães, pais, irmãos esposas e maridos e nesse período estão com os todos em casa. Assim, precisam administrar a vida de adultos, crianças e adolescentes, muitos, ainda, estão tendo que conciliar atividades profissionais remotas com as atividades acadêmicas. Conseguir organizar o tempo para realizar as diversas tarefas acadêmicas, profissionais e domésticas é um desafio quase que impossível para grande maioria dos respondentes. Outro fator bastante ressaltado é a falta de disciplina para manter a concentração durante as aulas remotas e manter o foco nos estudos. A falta de contato com outros estudantes e com o próprio espaço físico da universidade desestimula muitos estudantes a manter a rotina de estudos, assim como o foco no curso. Uma das dificuldades bastante relatada é o descaso com que a IES tem tratado o estudante: "só informa e deixa a gente se virar". Em muitos casos a falta de orientação dos professores e o medo de obter informações erradas na Internet provocam incertezas e desânimo e a consequente falta de qualidade no ensino. Esse discurso revela a relação Rev. Nova Paideia -Revista Interdisciplinar em Educação e Pesquisa Brasília/DF, v. 2, n. 3. Núm. Esp.. p. 3 - 17 - ANO 2020 ISSN 2674-5976 
entre a autonomia do estudante e a mediação didático-pedagógica estabelecida no processo ensino-aprendizagem. Como ressalta Masetto (2000), a tecnologia não possui fim em si mesma e depende da mediação do professor, ou seja, da postura dele como orientador, como direcionador do processo de construção do conhecimento.

Os docentes apontam que as maiores dificuldades na organização e gestão do tempo estão associadas a ter uma rotina para desenvolver o trabalho em Home Office. Muitos dizem que nesse período de pandemia trabalham mais que no presencial: "De segunda a segunda, mais de 12 horas diárias entre preparação de aulas, de atividades, correções, interações com estudantes, colegas e coordenação e reuniões institucionais ou treinamentos..." Apontam, ainda, que o acúmulo das atividades letivas com as demandas da família, dando suporte e apoio aos filhos tem sido muito estressante. A falta de capacitação em EaD provoca maior perda de tempo nos planejamentos e nas aulas em função do não domínio dos recursos tecnológicos. Nesse sentido, surgem dúvidas se "o que está sendo feito atende às especificidades da EaD", a instituição não oferece suporte pedagógico. Para instituição, muitas vezes, "basta 'pendurar' coisas que na plataforma que vai dar certo. Ou seja, o velho amadorismo e mediocridade dos que tem o poder da decisão na educação". Os docentes apresentam uma preocupação com o tempo no sentido de trabalharem muito e não conseguir fazer o acompanhamento pedagógico que acredita ser necessário para uma boa aprendizagem.

A terceira categoria diz respeito às dificuldades ambientais encontradas pelos respondentes. Nesse item os estudantes foram categóricos em afirmar que na maioria das casas não existe um espaço apropriado para os estudos, quando existe este espaço muitos fatores externos atrapalham na concentração, barulhos fora e dentro de casa e o acúmulo de pessoas no ambiente tornam o espaço inadequado para estudo. Outro fator bastante ressaltado é o de ter que dividir o espaço e materiais de estudo ou de trabalho (computadores, celulares e rede de internet) com outros membros da família. Dessa forma, o ambiente da residência neste momento não colabora com a eficácia nos estudos. Ao abordarem esta temática os docentes não apresentam uma realidade muito diferente das dos estudantes, uma vez que, tendo a família inteira dentro de casa o tempo todo um ambiente ou equipamento que era utilizado em horários diferentes pelos vários membros da família ficou mais disputado agora. Uma coisa que os docentes acrescentaram é a dificuldade em encontrar um ambiente adequado para a gravação das aulas.

A quarta categoria está relacionada às dificuldades psicológicas encontradas em tempos de isolamento social. Ao apresentarem tais dificuldades muitos estudantes afirmam que sua saúde mental está seriamente afetada no contexto que nos encontramos o que acarreta a "falta de motivação e preparo psicológico para focar nas aulas". Se sentem tomados por um sério sentimento de desmotivação em relação à academia na maior parte do tempo, não tendo vontade de dar continuidade ao curso, situação que se configura, para muitos, como dificuldades de aprendizagem. Afirmam, também, que o preparo psicológico muito abaixo do normal, acarreta na dificuldades em manter o ritmo de estudo. A falta de concentração, o estresse e a ansiedade foram bastante ressaltados nesse item. Dificuldades em lidar com a ansiedade, seja em relação ao contexto atual, ou com o formato das aulas e até mesmo com o desempenho nas Rev. Nova Paideia -Revista Interdisciplinar em Educação e Pesquisa Brasília/DF, v. 2, n. 3. Núm. Esp.. p. 3 - 17 - ANO 2020 ISSN 2674-5976 
atividades. Muitas vezes, tais questões psicológicas são agravadas pelo despreparo de alguns professores e pela falta de empatia dos mesmos, quanto ao estado psicológico dos alunos. Outro fator que tem afetado muito a questão psicológica se refereà pandemia, ao futuro e situações familiares. A dificuldade de manter a atenção durante as aulas, algo que, na maioria das vezes, não ocorria presencialmente está associada ao contexto social, que é estressante e atrapalha os estudos. Um elemento que apareceu em diversos comentários foi a falta de contato pessoal, a vontade de socialização e interação que ocorria no ambiente escolar, seja entre os estudantes, seja na relação professor e aluno. Esta falta de socialização se apresenta como um forte empecilho no processo de aprendizagem.

Em relação às dificuldades psicológicas os docentes afirmam que a maior delas está em não ver as pessoas, não ter o contato visual, se sentirem falando com a máquina, fazendo as aulas sem interação humana. Isso torna a atividade docente cansativa, frustrante e ineficiente. Muitos deles se sentem desafiados em manter estudantes ativos e participativos durante as aulas remotas, mas não obtêm sucesso e a desatenção dos estudantes os incomoda muito. Vale ressaltar que nem estudantes, nem docentes optaram por fazer as atividades de forma remota, esta foi uma imposição institucional provocada pela situação do isolamento social, portanto a realização de tais atividades afeta diretamente sua disposição psicológica.

Algumas questões foram específicas para os estudantes e outras específicas aos docentes. Passaremos agora a analisar as questões específicas aos estudantes: Foi perguntado aos estudantes como eles consideram o grau de orientação das atividades solicitadas pelos(as) professor(as) e na avaliação deles cerca de $80 \%$ considera que as orientações docentes são satisfatórias, enquanto que $22 \%$ consideram que pouco satisfatórias ou insuficientes. Dessas respostas podemos inferir que os estudantes se sentem bem orientados para realização das atividades propostas pelos docentes. Essa questão encontra algumas contradições em comentários de estudantes que se sentem sem orientações para a realização de suas atividades. Talvez, os comentários sejam pontos isolados, mas que merecem atenção.

Foi questionado como os estudantes consideram o tempo destinado à entrega das atividades solicitadas pelos professores. Como resposta obtivemos que $76 \%$ dos estudantes consideram satisfatório o tempo de realização das atividades, enquanto que apenas $24 \%$ avaliam o tempo como parcialmente ou pouco satisfatório.

Ao serem questionados sobre como consideram o preparo da maioria dos (as) professores (as) com relação às aulas não presenciais os estudantes afirmam que cerca de $70 \%$ dos docentes estão suficientemente preparados para as atividades de sala de aula, enquanto que $26,5 \%$ estão pouco ou mal preparados para realização dessas atividades.

No tocante ao contexto familiar no qual o estudante se encontra nesse período emergencial obtivemos as seguintes respostas: $39,7 \%$ afirmam que contexto familiar permite tempo mínimo de dedicação às atividades acadêmicas, outros 37,2 responderam que o contexto familiar permite dedicação exclusiva e cerca de 20 diz que

Rev. Nova Paideia -Revista Interdisciplinar em Educação e Pesquisa Brasília/DF, v. 2, n. 3. Núm. Esp.. p. 3 - 17 - ANO 2020 ISSN 2674-5976 
o contexto familiar não permite dedicação às atividades acadêmicas. 0 que nos leva a inferir que a maioria dos respondentes dispõe de tempo para realização das atividades propostas por meio remoto, mas um número significativo, cerca de 30 (vinte e cinco) estudantes no universo dos 121 (Cento e vinte e um) respondentes não conseguem tempo para realização das atividades o que está associado aos comentários realizados na categoria organização e gestão do tempo.

Passaremos, agora a analisar as questões que foram exclusivas aos docentes. A primeira questão dizia respeito à oferta de capacitação realizada pela instituição para realização das atividades remotas. 55,7\% dos docentes afirmaram que não foram capacitados, outros $25 \%$ disseram que fizeram uma capacitação muita rápida e insuficiente e apenas 19,3\% responderam que foram capacitados. Nesse sentido identificamos que mais de $80 \%$ dos respondentes não receberam a capacitação necessária e adequada para exercer as atividades remotas, isso demonstra a dificuldade em implantar ações de práticas a distância que requerem maior especialização dos professores para executá-las. Corrobora com as afirmações de Mill e Silva (2018), quando afirmar que entre as dificuldades em implantar ações de EAD está a dificuldade em encontrar e preparar recursos humanos qualificados para executar um trabalho de qualidade.

Quando interrogados sobre se já tinha realizado algum curso de capacitação docente para a modalidade de educação a distância, 55\% dos professores responderam que não e outros $45 \%$ que sim. Ou seja, mais da metade dos respondentes nunca foram capacitados para execução de atividades a distância. Mas curiosamente ao serem questionados sobre qual a sua experiência em EAD antes da pandemia, identificamos as seguintes porcentagens: $25 \%$ dos docentes afirmam que nunca tiveram experiência com EAD, 23,3\% dos respondentes afirmam que só tiveram experiências como estudantes na modalidade, outros 33,3\% já desenvolveram atividades na função de professor EAD, $23,3 \%$ desenvolveram atividades na função de Tutor, $16 \%$ como Supervisor e outros $16 \%$ como produtores de Materiais. Inferimos que grande parte daqueles que tiveram experiências como professores são os mesmos que exerceram função de tutores e de produtores de materiais. 0 que nos chama a atenção nesses dados são os $25 \%$ que nunca tiveram nenhum tipo de experiência com EAD. É bem provável que dentre os $55 \%$ que não receberam capacitação estejam estes $25 \%$ que nunca tiveram experiências com EAD, dado muito preocupante quando pensamos na qualidade de ensino que estes podem ofertar. Conforme afirmam Mill et al. (2014) a formação docente é um fator de extrema importância para que haja qualidade no ensino não presencial.

Ao serem questionados sobre em quais áreas consideram que precisam se aperfeiçoar para atuar em EaD obtivemos as seguintes respostas dos docentes: $56 \%$ afirmam que precisam se capacitar em metodologias didático-pedagógicas, $50 \% \mathrm{em}$ planejamento e desenho didático-pedagógico, 35\% no uso de tecnologias digitais da informação, $30 \%$ em produção de conteúdos educacionais, $26 \%$ em gestão e acompanhamento didático-pedagógico e outros $21 \%$ em mediação didático-pedagógica. Esses dados ratificam os apresentados na questão anterior e demonstram o quanto há de carência na formação continuada e no aperfeiçoamento dessa prática docente. 
Pelo fato de envolver muitas frentes de atuação o ensino a distância necessita de uma formação mais complexa do que o presencial. Como afirma Mill (2012) essa atividade introduz o conceito de polidocência, propõe um modelo de trabalho de equipe multidisciplinar com funções específicas que convergem para um produto final. Assim, a prática da docência é realizada a muitas mãos e com especializações bem distintas e por isso capacitações bastante específicas.

Quando questionados sobre qual plataforma ou quais recursos tecnológicos de informação e de comunicação estão sendo utilizados para realização das atividades remotas, os docentes responderam: 27,7\% MOODLE, 25,3\% Ferramentas Google (Class, Meet, Hangout...), 23,7\% Portal do estudante da própria IES, 16,6\% BLACKBOARD, 6,7\% GOOGLE MEET. Um fator que nos chama atenção aqui é que grande parte das instituições já tem seu próprio portal para desenvolver atividades a distância, quando juntamos os dados (Portal do estudante da própria IES mais Blackboard) identificamos que mais de $43 \%$ das instituições já fazem algum tipo de atividade a distância. Inferimos, também, que o Moodle, por ser um portal aberto, tem sido muito utilizado pelas IES. Por outro lado, aparece aqui mais uma curiosidade que é a utilização das ferramentas Google. Se juntarmos aqueles que responderam exclusivamente o Google Meet (pelo fato de estarem utilizando exclusivamente atividades síncronas) com os que afirmaram usar outras ferramentas Google teremos cerca de 30\% dos respondentes utilizando as ferramentas deste provedor. Este fato talvez se dê porque, em tempos de pandemia, a Google liberou o acesso a utilização dessas ferramentas a toda população.

Ao serem questionados sobre como consideram o tempo destinado à preparação das atividades cerca de $50 \%$ dos docentes responderam que o tempo é suficiente para preparar as atividades e 48,3\% consideram que o tempo não é suficiente. Inferimos que este dado esteja associado à dificuldade em elaborar ações que não fazem parte do cotidiano da maioria dos professores, Além de que o fato de estar em casa e acumularem outras atividades provocam dificuldades na organização do tempo como relatado na categoria organização e gestão do tempo.

\section{Considerações Finais}

Considerando que o presente estudo teve como objetivo identificar como as instituições de ensino superior - IES vem enfrentando o isolamento social na manutenção das atividades educacionais em tempos de pandemia, observamos que a maioria das instituições que mantiveram as atividades letivas são de natureza privada e que essas instituições, embora já realizem algumas ações educacionais a distância, a maioria dos professores respondentes não receberam a capacitação adequada para realizar as atividades remotas o que prejudica a qualidade da educação oferecida.

Por intermédio deste estudo identificamos quatro aspectos, categorizados como principais desafios e dificuldades enfrentados pelos professores e estudantes durante a realização das atividades não presenciais no período pandêmico: dificuldades tecnológicas; de organização e gestão do tempo; dificuldades ambientais e psicológicas.

Rev. Nova Paideia -Revista Interdisciplinar em Educação e Pesquisa Brasília/DF, v. 2, n. 3. Núm. Esp.. p. 3 - 17 - ANO 2020 ISSN 2674-5976 
Quanto às dificuldades tecnológicas, destacamos a falta de familiaridade dos professores com o uso das tecnologias associada à falta de capacitação e tempo necessário ao planejamento didático. Sobre o segundo aspecto, o acúmulo de outras demandas familiares resultantes do estado emergencial, associadas à falta de experiência e domínio das especificidades de práticas metodológicas a distância interfere negativamente na organização e gestão do tempo tanto dos estudantes quanto dos docentes. 0 aspecto ambiental relacionado a um espaço adequado para os estudos e realização das atividades escolares é considerado bastante difícil em razão do contexto de isolamento social em que todos se encontram. Esse aspecto interfere negativamente em fatores como concentração, engajamento e dedicação tanto de professores quanto de estudantes. Por fim, quanto aos aspectos psicológicos, ressaltamos a falta de interação no contexto da presencialidade física como um fator muito negativo para o processo de ensino-aprendizagem. Tanto docentes quanto estudantes não estavam preparados emocionalmente e pedagogicamente para vivenciar esse contexto que lhes foi imposto pelas IES.

Concluímos assim que as atividades não presenciais que estão ocorrendo no período pandêmico necessitam de uma atenção maior por parte das instituições de ensino superior considerando os aspectos elencados neste estudo. Embora se diferenciem da $\mathrm{EaD}$, em sentido conceitual, regulamentar e metodológico, às atividades não presenciais requerem cuidados apropriados, caso contrário não serão garantidos aos estudantes os direitos ao alcance dos objetivos de aprendizagem previstos nos respectivos planos de cursos. 0 caráter de distanciamento físico que caracteriza esse momento excepcional não pode ser remediado com práticas educacionais que desqualifiquem o trabalho do professor e causem prejuízos irreparáveis ao processo formativo dos nossos estudantes.

\section{Referências}

ALVES, Lucineia. Educação a distância: conceitos e história no Brasil e no mundo. Revista Brasileira de Aprendizagem Aberta e a Distância, São Paulo, V. 10, 83-92. Disponível em: https://doi.org/10.17143/rbaad.v10i0.235. Acesso em: 12/05/2020.

BELONI, Maria Luiza. Educação a distância. Campinas, Autores Associados: 2015.

BRASIL, Ministério da Educação. Decreto 9.057. de 25 de maio de 2017. Disponível em: http://www.in.gov.br/materia/-/asset publisher/Kujrw0TZC2Mb/content/id/ 20238603/do1-2017-05-26-decreto-n-9-057-de-25-de-maio-de-2017-20238503. Acessado em 20/05/2020.

CONSELHO NACIONAL DE EDUCAÇÃO - CNE. Parecer CNE CPN 5/2020. Publicado em 04/05/2020 eHomologado em 1/06/2020. disponível em https://www.semesp.org.br/wp-content/uploads/2020/05/Parecer-CNE-CP 5 20201.pdf-HOMOLOGADO.pdf. Acessado em 20/05/2020. 
MASETTO, Marcos T.. Mediação Pedagógica e o uso da Tecnologia. In MORAN, Manuel José; MASETTO, Marcos T.; BEHRENS, Marilda Aparecida. Novas tecnologias e mediação pedagógica. Campinas, Papirus: 2000.

MILL, Daniel. Docência Virtual: uma visão crítica. Campinas, Papirus: 2012.

Formação docente para a modalidade a distância na UAB-UFSCar: um olhar sobre o professor-coordenador de disciplina na polidocência. In: MILL, D. RIBEIRO, L. R. C.; OLIVEIRA, M. R. G. Polidocência na educação a distância: múltiplos enfoques. São Carlos, EdUFSCar: 2014.

Estudo sobre a constituição da polidocência na Educação a Distância. In: ALMEIDA, L. F., et al. Polidocência na educação a distância: múltiplos enfoques. $2^{2}$ ed. São Carlos: EdUFSCar, 2014b, p. 113-132.

; SILVA, Claeton Pedro Ribeiro da. Aprendizagem da Docência para Educação a Distância: uma breve revisão da literatura sobre docência virtual. Em Rede, Revista de Educação a Distância, Porto Alegre, v.5. n.3. 2018. Disponível em: https://www.aunirede.org.br/revista/index.php/emrede/article/view/377 Acessado em: $15 / 05 / 2020$.

PERES, Francisco Guitiérrez e CASTILHO, Daniel Prieto. La Mediación Pedagógica. Buenos Aires, Circcus: 1999.

SOUSA-SANTOS, Boaventura de. A Cruel Pedagogia do Vírus. Coimbra, Almedina: 2020. EbooK. 